\title{
Plasticity in the Rat Posterior Auditory Field Following Nucleus Basalis
}

\section{Stimulation}

\author{
Amanda C. Puckett,* Pritesh K. Pandya,* Raluca Moucha, WeiWei Dai, and Michael P. Kilgard \\ Neuroscience Program, School of Behavioral and Brain Sciences, University of Texas at Dallas, Richardson, Texas
}

Submitted 14 December 2007; accepted in final form 21 April 2007

\begin{abstract}
Puckett AC, Pandya PK, Moucha R, Dai WW, Kilgard MP. Plasticity in the rat posterior auditory field following nucleus basalis stimulation. J Neurophysiol 98: 253-265, 2007. First published April 25, 2007; doi:10.1152/jn.01309.2006. Classical conditioning paradigms have been shown to cause frequency-specific plasticity in both primary and secondary cortical areas. Previous research demonstrated that repeated pairing of nucleus basalis (NB) stimulation with a tone results in plasticity in primary auditory cortex (A1), mimicking the changes observed after classical conditioning. However, few studies have documented the effects of similar paradigms in secondary cortical areas. The purpose of this study was to quantify plasticity in the posterior auditory field (PAF) of the rat after NB stimulation paired with a high-frequency tone. NB-tone pairing increased the frequency selectivity of PAF sites activated by the paired tone. This frequency-specific receptive field size narrowing led to a reorganization of PAF such that responses to low- and mid-frequency tones were reduced by $40 \%$. Plasticity in A1 was consistent with previous studies-pairing a high-frequency tone with NB stimulation expanded the high-frequency region of the frequency map. Receptive field sizes did not change, but characteristic frequencies in A1 were shifted after NB-tone pairing. These results demonstrate that experience-dependent plasticity can take different forms in both A1 and secondary auditory cortex.
\end{abstract}

\section{N T R O D U C T I O N}

Neural plasticity in both the primary and the secondary sensory cortices has been associated with learning. After longterm operant training in primates and rats, large frequency map expansions can develop in response to trained tone frequencies in primary auditory cortex (A1) (Brown et al. 2004; Buonomano and Merzenich 1998; Polley et al. 2006; Recanzone et al. 1993; Rutkowski and Weinberger 2005; but see Brown et al. 2004). Long-term operant training can also cause frequencyspecific plasticity in secondary cortical areas (Polley et al. 2006). Classical conditioning shifts receptive fields in both primary and secondary auditory cortices toward the conditioned stimulus (Diamond and Weinberger 1984, 1986; Weinberger et al. 1984). A greater proportion of neurons in secondary cortical areas is altered by classical conditioning compared with A1 (Diamond and Weinberger 1984; Weinberger et al. 1984). Receptive field plasticity has also been observed in the somatosensory and visual systems, indicating that learninginduced plasticity is a general cortical phenomenon (Buonomano and Merzenich 1998; Ghose 2004; Gilbert 1996; Recan-

* These authors contributed equally to this work.

Address for reprint requests and other correspondence: A. Puckett, School of Behavioral and Brain Sciences, University of Texas at Dallas, P.O. Box 830688, Mail Station GR41, Richardson, TX 75083-0688 (E-mail: apuckett@utdallas.edu). zone et al. 1992a,b). In all of these cases, experience-dependent plasticity is specific to the stimuli that were attended to during behavior and passive exposure does not cause enduring changes in neuronal responses (Recanzone et al. 1993; Weinberger 1998; Weinberger and Bakin 1998). These results indicate that stimulus-specific plasticity occurs during learning and significantly alters sensory information processing in multiple cortical areas.

Many studies have demonstrated that attention or the presence of a neuromodulator such as acetylcholine is necessary to generate lasting cortical plasticity. Nucleus basalis (NB), which has cholinergic and GABAergic projections to all areas of the neocortex, is active when animals are learning new tasks (Butt and Hodge 1997; Richardson and DeLong 1991). Lesions of cholinergic NB neurons or pharmacological blockages of acetylcholine prevent both learning and plasticity in the motor cortex (Conner et al. 2003) and in A1 ( $\mathrm{Ji}$ et al. 2001). Direct stimulation of NB paired with sensory inputs is sufficient to create stimulus-specific cortical plasticity in A1 (Bakin and Weinberger 1996; Kilgard and Merzenich 1998a). For example, NB stimulation paired with a single tone results in an increased representation of the paired frequency in A1 (Kilgard and Merzenich 1998a). Therefore, similar to classical conditioning and operant conditioning protocols, NB-stimulation pairing leads to stimulus-specific plasticity in A1. The extent of NB-stimulation-induced receptive field reorganization outside of A1 has not been well characterized.

In this study, we implanted rats with NB-stimulating electrodes, repeatedly paired a high-frequency tone with NB stimulation, and documented differences in posterior auditory field (PAF) responses to tones in experimental and control rats. Because PAF responses are much less selective than A1 for frequency (Bao et al. 2001; Doron et al. 2002; Rutkowski et al. 2003; PK Pandya, DL Rathbun, ND Engineer, R Moucha, and MP Kilgard, unpublished observations), we expected that plasticity after NB-tone pairing would differ substantially from observations in A1. One possibility, given the broad frequency tuning, was that NB-tone pairing would generate a frequencyspecific reduction in the response to frequencies distant from the paired tone. If observed, such plasticity would suggest that the increased response to events associated with neuromodulator release observed in primary sensory and motor cortex may not be characteristic of plasticity in other fields (Buono-

\footnotetext{
The costs of publication of this article were defrayed in part by the paymen of page charges. The article must therefore be hereby marked "advertisement" in accordance with 18 U.S.C. Section 1734 solely to indicate this fact.
} 
mano and Merzenich 1998; Conner et al. 2003; Weinberger 2007).

\section{METHODS}

Six adult female Sprague-Dawley rats (250-350 g) were implanted with platinum bipolar stimulating electrodes and then exposed to a $19-\mathrm{kHz}$ tone paired with NB stimulation for a period of 20-25 days. After $24 \mathrm{~h}$, animals were anesthetized and the right auditory cortex was densely mapped by recording tuning curves. Receptive field properties and topographic organization of both primary (A1) and posterior (PAF) auditory fields were quantified. Data from naïve controls $(n=14)$ served as comparisons for all the NB-stimulated animals. Additionally, mapping data from an animal that experienced a 9-kHz tone paired with NB stimulation during a previous study were analyzed to ensure that plasticity in PAF was frequency specific. The A1 map for this animal is depicted in Fig. $1 C$ of Kilgard and Merzenich (1998a). Analysis of thresholds and frequency range of neural responses indicate every rat had normal hearing (data not shown). The implantation, stimulation, and mapping methods described here are identical to those used in previous studies (Kilgard and Merzenich 1998a; Kilgard et al. 2001; Moucha et al. 2005; Pandya et al. 2005). All procedures were approved by the University of Texas at Dallas Animal Care and Use Committee.

\section{Implantation with NB-stimulating electrode}

Each experimental animal was implanted with a bipolar stimulating electrode (SNE-200, Rhodes Medical Instruments, Woodland Hills, $\mathrm{CA}$ ), which was lowered $7 \mathrm{~mm}$ below the cortical surface from a location $2.3 \mathrm{~mm}$ posterior and 3.3 lateral to bregma in the right hemisphere. This stereotaxic location was used in previous studies of plasticity after NB-stimulation pairing (Bakin and Weinberger 1996; Dimyan and Weinberger 1999; Kilgard and Merzenich 1998a,b, 2002; Kilgard et al. 2001; Moucha et al. 2005; Pandya et al. 2005) and was
A
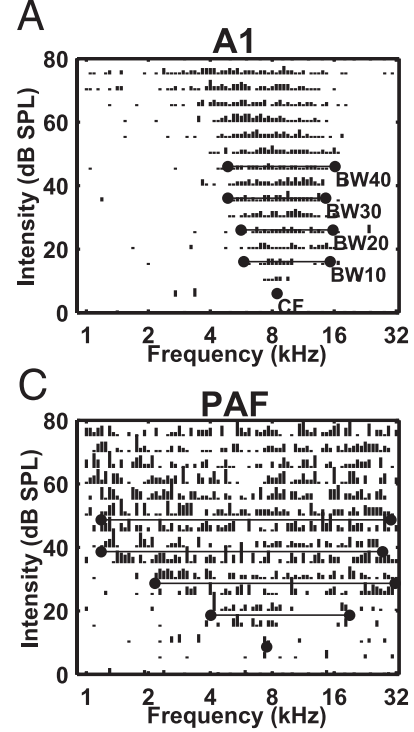

B
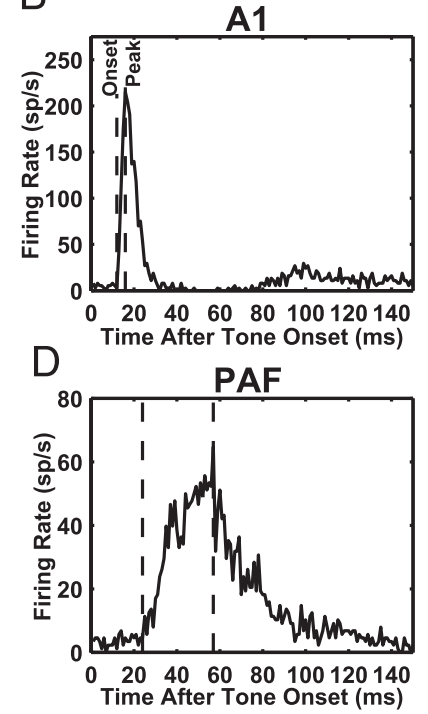

FIG. 1. Representative tuning curves and poststimulus time histograms (PSTHs) demonstrating the larger receptive field sizes and longer latencies of posterior auditory field (PAF) sites compared with primary auditory cortex (A1) sites. $A$ and $C$ : receptive field characteristics quantified for each site: characteristic frequency $(\mathrm{CF})$, threshold, bandwidth $10 \mathrm{~dB}$ above threshold (BW10), BW20, BW30, and BW40. $B$ and $D$ : a PSTH for each site was constructed from all of the responses within each site's receptive field. Peak, onset, and end of peak latency for each site were then calculated from the PSTH (see METHODS). not histologically confirmed in the current study. A bone screw was placed approximately $5 \mathrm{~mm}$ posterior to the stimulating electrode and another screw placed above the cerebellum to record an electroencephalogram (EEG). A four-channel connector was used to monitor EEG and deliver current to the stimulating electrode. The entire implant assembly was stabilized with additional bone screws and held in place with dental acrylic. In addition to the pentobarbital anesthetic $(50 \mathrm{mg} / \mathrm{kg})$, all animals were given a dose of ceftriaxone antibiotic (20 $\mathrm{mg} / \mathrm{kg}$ ) to prevent infection and atropine $(1 \mathrm{mg} / \mathrm{kg})$ and dexamethazone $(4 \mathrm{mg} / \mathrm{kg})$ to reduce fluid accumulations in the lungs immediately after anesthetization and after completion of the surgery. All animals were allowed to recover for 1-2 wk before beginning NB stimulation. Animals were singly housed in wire cages in the animal care facility after the NB-stimulation implant procedure and between NB-stimulation sessions.

\section{$N B$-stimulation procedure}

NB stimulation took place in a $25 \times 25 \times 25$-cm wire cage located inside of a $50 \times 60 \times 70$-cm chamber lined with acoustic insulating foam. Sounds were presented from a speaker hanging above the wire cage. The paired stimulus was a $19-\mathrm{kHz}$ tone (50 dB SPL, 250-ms duration, 5-ms rise-fall time) that was presented approximately every 10 s 275-350 times per day for a period of 20-25 days. Silent intervals were inserted at random to prevent habituation and each pairing session lasted approximately $3.5 \mathrm{~h}$. Each tone presentation was accompanied by a short burst of current delivered to the bipolar stimulating electrode (20 biphasic pulses, $0.1-\mathrm{ms}$ duration at $100 \mathrm{~Hz}$ ) approximately $5 \mathrm{~ms}$ after tone onset. The current amplitude ranged from 120 to $200 \mu \mathrm{A}$ for each animal and was selected to be the level that would reliably elicit brief EEG desynchronization while the animal was in slow-wave sleep.

\section{Dense electrode mapping of auditory cortex}

Approximately $24 \mathrm{~h}$ after the tone-NB-pairing phase ended, animals were anesthetized with pentobarbital $(50 \mathrm{mg} / \mathrm{kg})$ and the right auditory cortex was mapped. Similar mapping procedures were used to collect data from 14 experimentally naïve control animals. Because only NB-stimulated animals received connectors and acrylic headcaps used for NB stimulation, it was impossible to be blind to the experimental group during data collection. Briefly, a tracheotomy was performed to prevent breathing problems and head noise, and a cisternal drain was made to minimize cerebral edema. Then the right auditory cortex was exposed and the dura resected. The cortex was maintained under a thin film of silicone oil to prevent desiccation. Fluids with Ringer solution and supplemental anesthetic (pentobarbital, $8 \mathrm{mg} / \mathrm{ml}$ ) were periodically administered throughout the mapping procedure to maintain the animal's health and a state of areflexia.

All recordings were performed in a shielded, double-walled sound chamber. Frequency and intensity calibrations were performed with an ACO Pacific microphone (PS9200-7016) and Tucker-Davis Technologies (TDT, Alachua, FL) SigCal software. The speaker (Motorola model \#40-1221) was positioned directly opposite the contralateral ear at a distance of $10 \mathrm{~cm}$. TDT hardware and software (SigGen) were used for stimulus generation. Multiunit responses were recorded using parylene-coated tungsten electrodes $(250-\mu \mathrm{m}$ separation, $2 \mathrm{M} \Omega$ at $1 \mathrm{kHz}$; FHC, Bowdoinham, $\mathrm{ME})$ that were lowered approximately $50 \mu \mathrm{m}$ below the cortical surface (layer IV/V). The neural signal was filtered $(0.3-8 \mathrm{kHz})$ and amplified $(\times 10,000)$. Action potential waveforms were captured using a software program (Brainware, TDT) and each recording site location was logged on a detailed digitized photo of the exposed auditory cortex using blood vessels as landmarks. At each site, a tuning curve consisting of 81 frequencies spanning from 1 
to $32 \mathrm{kHz}$ at 16 intensities spanning from 0 to $75 \mathrm{~dB}$ SPL was presented (1,296 tones, 25-ms duration, 5-ms rise-fall time, one repetition of each). The tones were randomly interleaved and presented every $500 \mathrm{~ms}$. The total duration of each mapping experiment was similar in naïve and experimental groups $(31 \pm 1.2$ and $26 \pm 1.9 \mathrm{~h}, P>0.1)$.

\section{Data analysis}

In total, 493 experimental sites (six animals; 295 A1 and 198 PAF sites) were compared with 588 sites from naïve controls (14 animals total; 390 A1 and 198 PAF sites). For the naïve control groups, the A1 group consisted of eight animals, whereas the PAF group contained nine animals (three naïve controls belonged to both the A1 and PAF control groups). The control group for each cortical field was selected so that every animal had $\geq 10$ recording sites in the given auditory field. All experimental animals met this criterion for both A1 and PAF.

\section{Tuning curve analysis}

All sites from control and experimental rats were analyzed together in a blind, randomized batch to prevent experimenter bias. Several receptive field and latency characteristics were defined at each site. The lowest intensity that evoked a reliable neural response was defined as the threshold; the frequency at which this response occurred defined the characteristic frequency $(\mathrm{CF})$. Four bandwidths (BW10-BW40) were calculated as the range of frequencies (measured in octaves) that evoked reliable responses at 10, 20, 30, and $40 \mathrm{~dB}$ above threshold (Fig. 1, $A$ and $C$ ). A poststimulus time histogram (PSTH) was constructed from all of the responses to tone-intensity combinations within the receptive field using 1-ms-width bins. The spontaneous firing rate at each site was estimated as the spike rate in the first $9 \mathrm{~ms}$ recorded after tone onset (before any neural response to sounds). The peak latency for each site was calculated as the time of the maximum number of spikes in the PSTH (Fig. 1, $B$ and $D$ ). The onset latency was the first time point in the PSTH when response strength reached 2 SDs above the spontaneous firing rate for a consecutive period of $2 \mathrm{~ms}$. Onset latency was examined only in sites with thresholds $<35 \mathrm{~dB}$ SPL to ensure that the presented tones were sufficiently loud to evoke the shortest possible response latency. For all of these measures, experimental and control groups were compared using two-tailed unpaired Student's $t$-test to determine whether there were statistically significant differences in receptive field or response characteristics after NB-stimulation pairing.

\section{Topography and map expansions}

A1 was functionally defined on the basis of latency and tonotopy (Kilgard and Merzenich 1999). In general, sites with peak latencies $<20 \mathrm{~ms}$ were classified as A1. Only $4 \%$ of A1 sites in this study exhibited longer latencies. The A1-PAF border was defined using the previously characterized change in topography and latency (Bao et al. 2001; Doron et al. 2002; Rutkowski et al. 2003; PK Pandya, DL Rathbun, ND Engineer, R Moucha, and MP Kilgard, unpublished observations). The dorsal and ventral borders of A1 were also defined by changes in topography and latency, whereas the anterior border of A1 was defined primarily by a reversal in topography. Other boundaries were defined using sites nonresponsive to auditory stimuli or, in some cases, the limits of data collection.

Changes in cortical tone frequency representation were quantified by comparing the distribution of receptive field tuning (CFs) in experimental animals to naïve control animals. Because the percentage of sites with CFs in any given frequency range could be biased if the spacing of recording sites was not even across the cortical surface (i.e., as a result of blood vessels), we also used the percentage of cortical area measure used in earlier studies (Kilgard and Merzenich 1998a). Briefly, Voronoi tessellation was used to transform the discretely sampled surface into a continuous map using the assumption that each point on the map has the response characteristics of the nearest recording site. Because regions with above-average sampling density have smaller tessellations, they do not bias estimates of the cortical response. The percentage of the cortical area responding to each tone was estimated as the sum of the areas of all tessellations from sites (in A1 or PAF) with receptive fields that included the tone divided by the total area of the field. Changes in PAF and A1 frequency representation were quantified by comparing the percentage of the cortical area of each field that responded to all presented tones in the tuning curve in naïve and experimental animals. Two-tailed unpaired Student's $t$-tests were used to determine the statistical significance of all comparisons.

\section{RES U L T S}

Pairing NB stimulation with a $19-\mathrm{kHz}$ tone shifted the response of $\mathrm{A} 1$ and $\mathrm{PAF}$ neurons to favor high-frequency tones over low-frequency tones and increased frequency selectivity in PAF. In A1 the bias for high frequencies results from receptive field shifts with little change in bandwidth. In PAF the bias results from a reduction of the PAF response to low-frequency tones.

\section{Classification of primary and posterior auditory cortical fields}

The A1 of each animal was defined by its location, tonotopic organization, narrow bandwidths, and short latencies. The CF of sites increases systematically from posterior to anterior across the surface of A1. Receptive field sizes in A1 were narrower than PAF sites (Fig. 1, $A$ and $C$ ). In both control and experimental animals, the bandwidths $30 \mathrm{~dB}$ above threshold of A1 neurons were about 2 octaves (Fig. 2, $C$ and $D$ ). The peak latencies for A1 sites were shorter than PAF, usually within 10-20 ms after tone onset (Fig. 1B). There was no significant change in A1 latencies in experimental animals compared with control animals (onset latency: control, $12.3 \pm$ 0.2 ; experimental, $12.0 \pm 0.2, P=0.19$; peak latency: control, $18.0 \pm 0.4$; experimental, $19.4 \pm 0.7, P=0.06)$.

The PAF was defined based on its location posterior to A1, poor tonotopic organization, large receptive field sizes, and long response latencies. The anterior border of PAF was defined by the low-frequency edge of A1, whereas dorsal and ventral borders of PAF were defined by sites that were nonresponsive to tones. The far posterior border of PAF was often not as well demarcated because access was limited by the edge of the craniotomy. Although the CFs of A1 sites in controls were fairly evenly distributed (in log space) between 1 and 32 $\mathrm{kHz}$, a relatively large number of PAF sites were tuned to frequencies between 5 and $8 \mathrm{kHz}$ (Fig. 2A). Receptive fields in PAF of control animals often spanned $>3$ octaves at BW30 (see example map in Fig. 2C), and many sites responded to all tones within the rat's hearing range (Fig. $1 C$ ). The clustering of PAF CFs toward mid-frequencies may result from the large receptive field sizes and lower mid-frequency hearing thresholds of rats (Kelly and Masterton 1977). The peak latencies in PAF for both control and experimental animals were significantly longer than those in A1, between 30 and $80 \mathrm{~ms}$ (Fig. 1, $B$ and $D$ and Fig. 2, $E$ and $F$ ). NB-tone pairing did not 
A

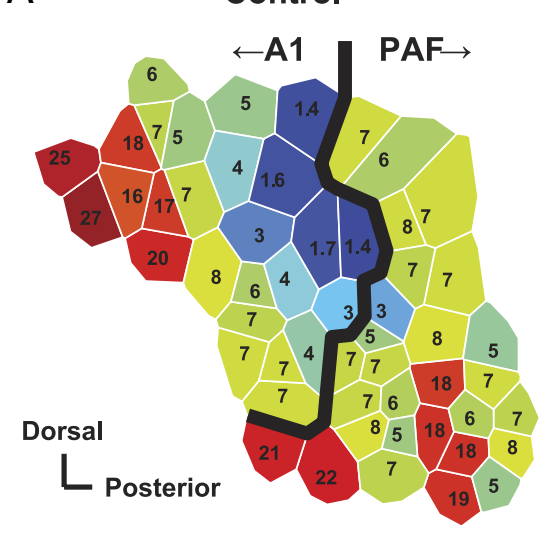

C

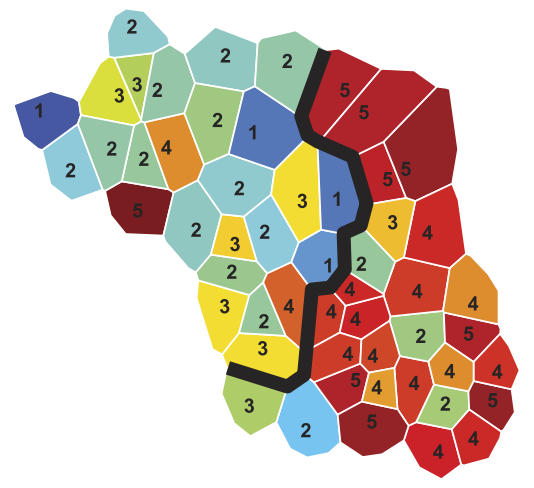

$E$

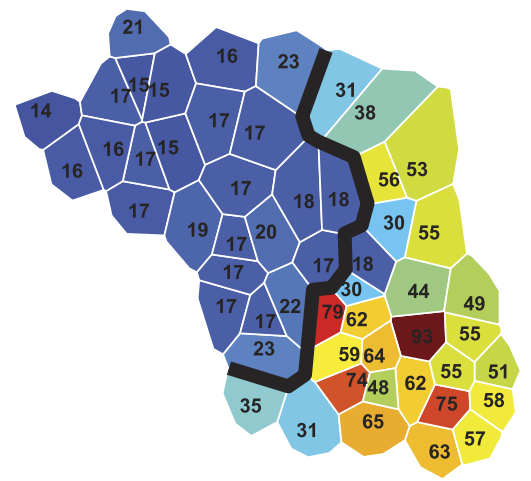

$B$
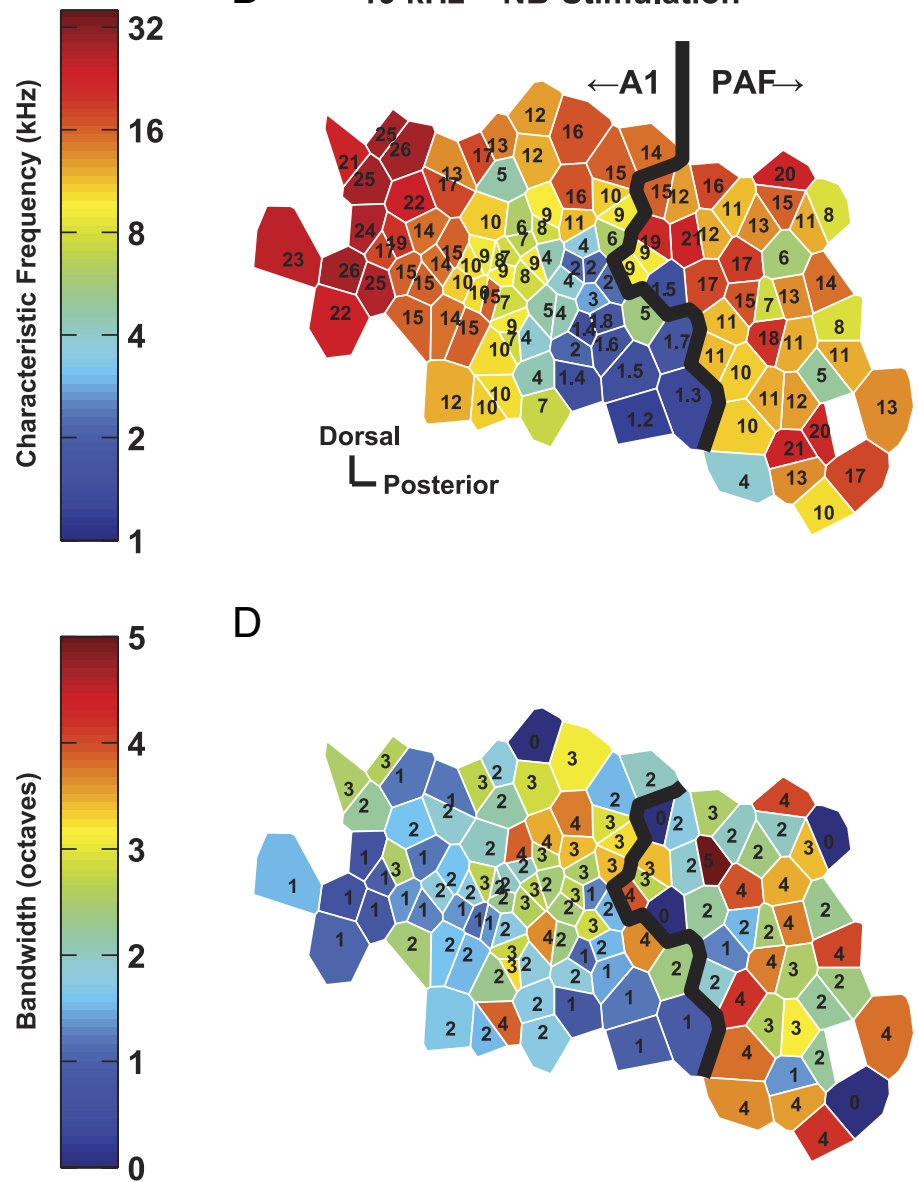

$\mathrm{F}$

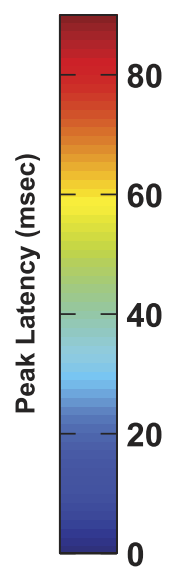

B $19 \mathrm{kHz}+\mathrm{NB}-$ Stimulation

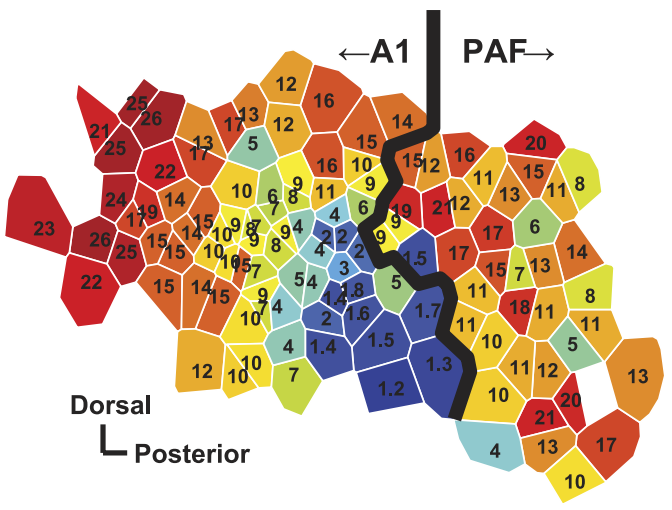

D

80

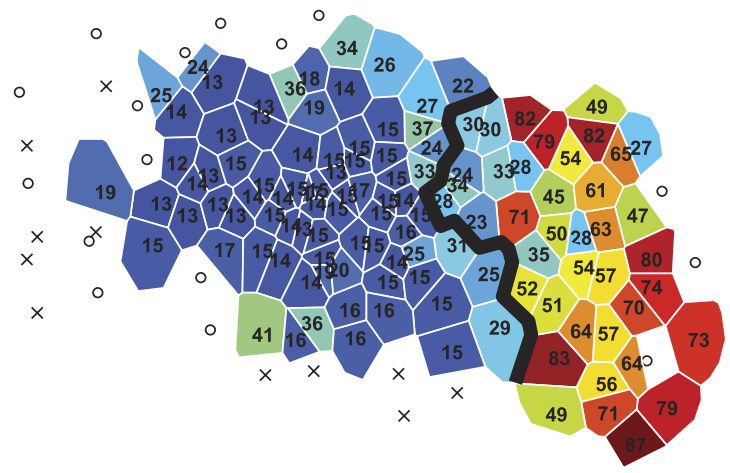

FIG. 2. Maps of A1 and PAF in an example control (left column) and experimental animal (right column) demonstrate the high-frequency map expansion and decreased bandwidths after nucleus basalis $(\mathrm{NB})$-stimulation paired with a $19-\mathrm{kHz}$ tone. Each polygon represents a single electrode penetration. Color of each polygon represents the value of the $\mathrm{CF}(A$ and $B)$, bandwidth $30 \mathrm{~dB}$ above threshold $(C$ and $D)$, or peak latencies $(E$ and $F)$ of the site. Thick black line indicates the border between A1 and PAF. Responses that did not respond to tones are indicated by an open circle $(F)$. Sites that responded to tones but did not meet our definition of A1 or PAF are indicated by an $\times(F)$. The example control map did not have any sites that belonged to other auditory fields or any nonauditory sites. This map was selected for this illustration because of the large number of sites in both A1 and PAF. Most control maps focused on either A1 or PAF and were bounded by recording sites that were either nonresponsive, non-A1, or non-PAF. Scale bars in $A$ and $B$ indicate a distance of 0.125 mm.

significantly alter response latencies in PAF (peak latency: control: $53.1 \pm 2.2 \mathrm{~ms}$, experimental: $54.1 \pm 2.3 \mathrm{~ms}, P=$ 0.75 ; onset latency: control: $35.0 \pm 1.7$, experimental: $31.8 \pm$ $1.2, P=0.14)$.

\section{Example of plasticity in primary and posterior} auditory fields

Data from an example control and an example experimental map are shown in Fig. 2 to demonstrate the effects of NB-tone 
pairing in A1 and PAF (Fig. 2). NB stimulation paired with a $19-\mathrm{kHz}$ tone increased the area of A1 that responded to high-frequency tones. Whereas $35 \%$ of A1 responded to a 19-kHz $60 \mathrm{~dB}$ SPL tone in the example control animal (Fig. 2, $A$ and $C), 54 \%$ of $\mathrm{A} 1$ responded to the same tone in an NB-stimulated animal (Fig. 2, $B$ and $D$ ). In our example experimental animal, NB stimulation paired with a $19-\mathrm{kHz}$ tone decreased the area of the PAF cortex that responded to low-frequency tones, but did not increase the total area of PAF that responded to high-frequency tones. Whereas $82 \%$ of PAF responded to a $2-\mathrm{kHz} 60 \mathrm{~dB}$ SPL tone in the example control animal (Fig. 2, $A$ and $C$ ), only $56 \%$ of PAF responded to the same tone in an NB-stimulated animal (Fig. 2, $B$ and $D$ ). In the control and experimental animals, 94 and $82 \%$ of PAF responded to a $19-\mathrm{kHz} 60 \mathrm{~dB}$ SPL tone, indicating that the major effect of NB-tone pairing may have been to decrease responses to unpaired tones rather than increase responses to the paired tone. After NB stimulation, PAF tuning curves in the experimental animal were narrower than the control map, and many more sites had CFs between 11 and $20 \mathrm{kHz}$ (Fig. 2B). In the representative control animal, the average bandwidth of PAF sites was $3.9 \pm 0.17$ octaves, whereas the average bandwidth of PAF sites in the representative experimental animal was only $2.92 \pm 0.16$ octaves (Fig. 2, $C$ and $D$ ). These two example maps illustrate that both $\mathrm{A} 1$ and PAF exhibit shifts in their frequency tuning to favor high frequencies after NB stimulation paired with a $19-\mathrm{kHz}$ tone. However, only the secondary cortical area (PAF) showed increased frequency selectivity.

\section{Topography in Al and PAF}

All A1 maps in the control group had large, significant coefficients of determination between anterior-posterior location and CF (average $r^{2}$ for A1 in control animals: $0.79 \pm$ 0.02 ). NB-tone pairing did not eliminate the tonotopic organization of A1 (average $r^{2}$ for A1 in experimental rats: $0.79 \pm$ 0.05). PAF showed evidence of weak tonotopic organization in control animals that was eliminated after NB-tone pairing. When all PAF sites from all nine control animals were examined together, we found a weak, but statistically significant, correlation between each site's anterior-posterior position (relative to the A1-PAF border) and $\mathrm{CF}\left(r^{2}=0.09, P<10^{-5}\right.$; Fig. $3 A$ ). When each animal was considered separately, only three of the nine control rats showed significant correlations between position and CF (average $r^{2}$ for PAF in control rats: $0.15 \pm$ $0.05)$. In the experimental group, there was no evidence of tonotopic organization when all PAF sites from all animals were grouped together $\left(r^{2}=-0.09, P=0.23\right.$; Fig. $\left.3 B\right)$. Only one of the six experimental animals showed any evidence of tonotopic organization in PAF when considered individually (average $r^{2}$ for PAF in experimental rats: $0.07 \pm 0.05$ ). We did not observe significant increases in the overall area of either A1 or PAF after NB-stimulation pairing (A1: $1.94 \pm 0.26$ vs. $1.48 \pm 0.17 \mathrm{~mm}^{2}, P=0.13$; PAF: $1.28 \pm 0.22$ vs. $0.89 \pm 0.18$ $\left.\mathrm{mm}^{2}, P=0.15\right)$.

\section{NB stimulation reduced PAF responses to low-frequency tones}

NB stimulation paired with a $19-\mathrm{kHz}$ tone resulted in an increase in the proportion of sites in PAF that were tuned to
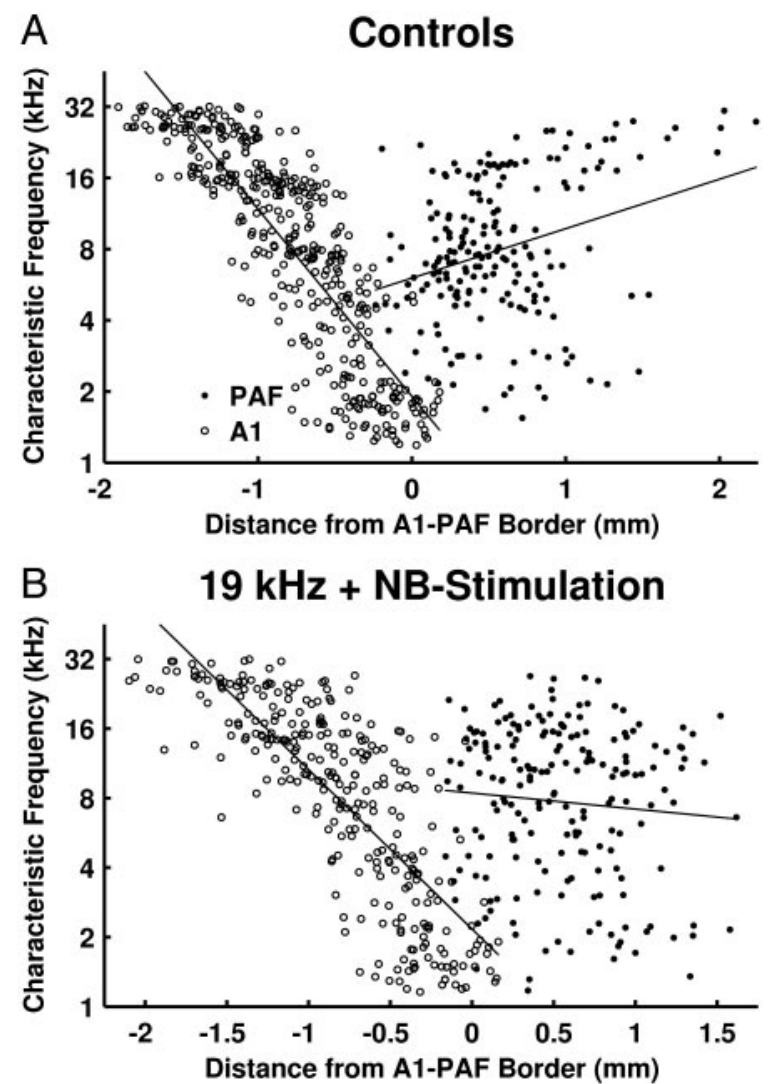

FIG. 3. Scatterplots of A1 and PAF with best-fit lines demonstrate that PAF is more loosely tonotopically organized than A1. To normalize for irregular borders and differing sizes of the A1 and PAF fields between animals, the A1 and PAF border was chosen as the mean position between the most posterior A1 site and most anterior PAF site. Because the border between $\mathrm{A} 1$ and PAF is frequently irregular, some A1 sites were located further posterior than the most anterior PAF site. A1 sites are denoted by open circles; PAF sites are denoted by points in the plot for controls $(A)$ and for NB-stimulated animals $(B)$.

high frequencies (Fig. 4). In experimental animals, a larger percentage of sites had CFs that fell within 0.5 octave of 16 $\mathrm{kHz}$ than control animals (mean percentage of total PAF sites in the $16-\mathrm{kHz}$ bin for each animal: controls: $22 \pm 5 \%$; experimental: $37 \pm 10 \%, P=0.11$ ). In experimental animals, $28 \pm 4 \%$ of PAF sites had CFs within 0.5 octave of $8 \mathrm{kHz}$, compared with $41 \pm 6 \%$ in naïve controls $(P=0.11)$. There was no difference in the percentage of sites falling into the 2or $4-\mathrm{kHz}$ centered bins (Fig. 4). These results are consistent with a shift in the CF of initially mid-frequency tuned sites (i.e., in the $8-\mathrm{kHz}$ bin) toward the tone frequency paired with NB stimulation. In the one animal that experienced a $9-\mathrm{kHz}$ tone paired with NB stimulation, the percentage of PAF sites in the 2- and $4-\mathrm{kHz}$ bins (4 and $0 \%$, respectively) were also decreased compared with naïve controls, providing further indication that the shift in tuning in PAF after NB-tone pairing was frequency specific.

Pairing NB stimulation with a $19-\mathrm{kHz}$ tone increased tonefrequency selectivity in PAF. The average bandwidth $30 \mathrm{~dB}$ above threshold (BW30) decreased by $17 \%$, from $3.6 \pm 0.08$ octaves in controls to $3.0 \pm 0.08$ octaves in experimental animals $\left(P<10^{-7}\right)$. Sites tuned to higher frequencies exhibited the largest reduction in BW. For sites with CFs within 0.5 octave of $16 \mathrm{kHz}$, receptive fields were significantly narrower 


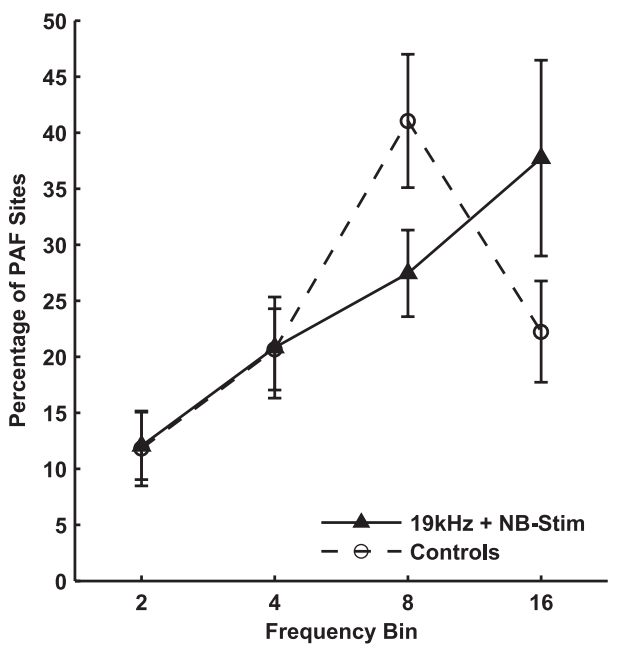

FIG. 4. Histogram of the proportion of PAF sites $( \pm$ SE) for each control or experimental group with $\mathrm{CF}$ falling into each of 4 frequency bins, demonstrating the shift in tuning of PAF sites after NB-tone pairing. One-octave-wide bins are centered on $2,4,8$, and $16 \mathrm{kHz}$.

at each analyzed suprathreshold intensity (Fig. 5). For example, BW30 of sites in the $16-\mathrm{kHz}$ bin decreased by $30 \%$, from $3.8 \pm 0.14$ octaves in control animals to only $2.7 \pm 0.18$ octaves in experimental animals $\left(P<10^{-6}\right)$. Mid-frequency sites $(8-\mathrm{kHz}$ bin) showed a more modest bandwidth decrease and the low-frequency bins did not show any change in bandwidths at any intensity above threshold (Fig. 5).

The frequency-specific nature of the bandwidth decrease in PAF suggests the possibility that only sites that were activated by the $19-\mathrm{kHz}$ tone paired with NB stimulation became more frequency selective, whereas sites that did not respond to the $19-\mathrm{kHz}$ tone were unaffected. All PAF sites in both the control and experimental groups were subdivided into those whose
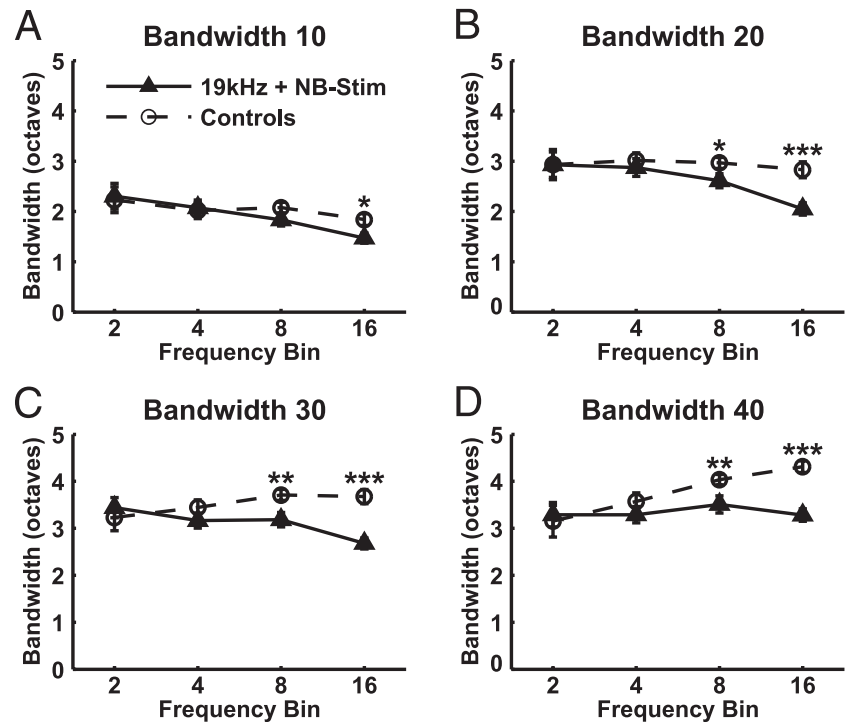

FIG. 5. Average bandwidth of PAF experimental sites decreased compared with controls in high-frequency bins across all 4 bandwidth measures (BW10BW40). Each plot shows the average bandwidth $( \pm \mathrm{SE})$ in control and experimental sites with CFs within each frequency bin for a different bandwidth measure. Asterisks indicate significance values of a $t$-test comparing control and experimental sites in each frequency bin: $* P<0.05 ; * * P<0.01$; $* * * P<0.001$.
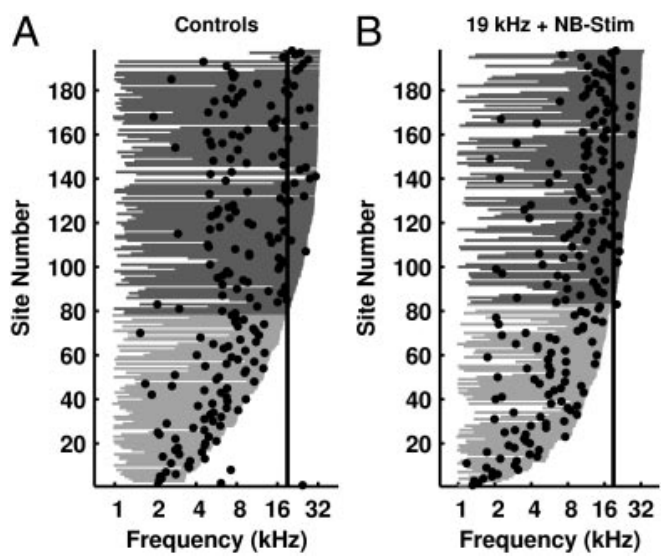

FIG. 6. NB-tone pairing narrows frequency tuning and shifts CFs toward the paired-tone frequency $(19 \mathrm{kHz})$. Every PAF recording site for controls $(A)$ and experimental animals $(B)$ is shown sorted by the highest frequency contained within its receptive field for $50 \mathrm{~dB}$ SPL tones. Sites that included 19 $\mathrm{kHz}$ within their receptive field are plotted in dark gray, whereas sites that did not are depicted in light gray. Black circles denote the assigned CF of each site. Vertical black line on each panel is located at $19 \mathrm{kHz}$.

receptive fields included $19 \mathrm{kHz}$ played at $50 \mathrm{~dB}$ SPL (Tone In) and those that did not (Tone Out) (Fig. 6). As expected based on the selection criteria, the average bandwidth of the Tone In subset of sites was significantly larger than the average bandwidth of the Tone Out subsets in both control and experimental animals (Fig. 7). The Tone In subset included not only sites that had CFs near the paired tone, but also virtually all broadly tuned sites (i.e., with bandwidths $>4$ octaves) regardless of their assigned best frequency (Fig. 6). NB-tone pairing decreased the bandwidth of the Tone In subset, whereas the Tone Out subset of PAF sites remained unchanged (Fig. 7). The average bandwidth $40 \mathrm{~dB}$ above threshold (BW40) of Tone In sites dropped by 0.79 octave after NB-tone pairing, from $4.23 \pm 0.12$ octaves in control animals to $3.44 \pm 0.12$ octaves in experimental animals $\left(P<10^{-5}\right)$. Pairing did not alter the

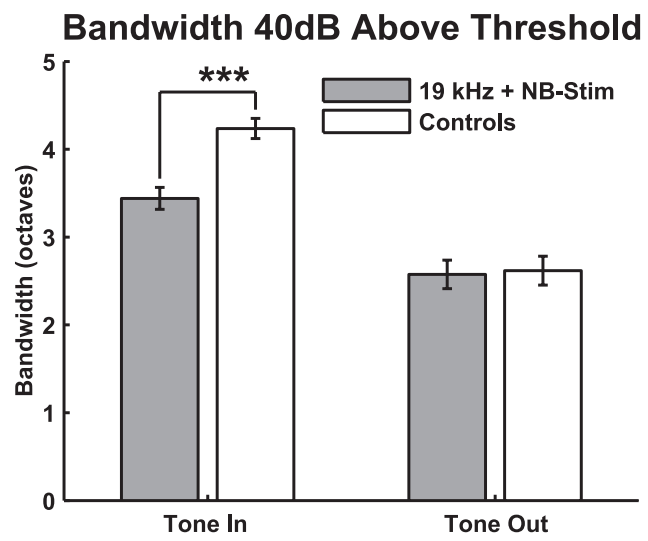

FIG. 7. Average bandwidth of PAF sites that contained the paired tone (19 $\mathrm{kHz}, 50 \mathrm{~dB}$ SPL) in their receptive field (Tone In) were decreased in control vs. experimental animals. Tone Out sites did not change their receptive field sizes. BW40 was chosen for this measure because the paired tone fell closer to BW40 than other bandwidth measures in the receptive field of most PAF sites. However, the same pattern of results was observed for all bandwidth measures. Asterisks indicate level of significance: $* P<0.05$; $* * P<0.01$; $* * P<0.001$. Average bandwidths of Tone In sites were significantly larger than the average bandwidths of Tone Out sites in both control and experimental animals (see RESULTS). 
average bandwidth of Tone Out sites (BW40 in octaves of Tone Out sites: controls: $2.62 \pm 0.16$; experimentals: $2.58 \pm$ $0.16, P=0.85)$. These results imply that plasticity in PAF may have been restricted to those sites that were able to respond to the paired tone before NB-tone pairing began.

The increase in frequency selectivity in sites that responded to the $19-\mathrm{kHz}$ tone paired with NB stimulation produced a decrease in the percentage of PAF that responded to low-frequency tones. Although $87 \pm 3.2 \%$ of PAF responded to a $2-\mathrm{kHz}$ tone played at $60 \mathrm{~dB}$ SPL in the control rats, only $53 \pm 6.1 \%$ of PAF responded after NB stimulation paired with a $19-\mathrm{kHz}$ tone $(P=0.0001$, Fig. $8 B$ ). Thus $39 \%$ fewer sites responded to the $2-\mathrm{kHz} 60 \mathrm{~dB}$ SPL tone in experimental animals compared with naive control animals. This decrease in responsiveness to low-frequency tones was observed for all tones with frequencies $<5 \mathrm{kHz}$ played at intensities within the rat's hearing range. In contrast, there was only a modest increase in the percentage of PAF cortex that responded to high-frequency tones (Fig. 9). For example, the percentage of PAF that responded to a $16-\mathrm{kHz} 60 \mathrm{~dB}$ SPL tone increased from $65.7 \pm 6.9 \%$ in control animals to $73.7 \pm 6.3 \%$ of PAF in experimental animals $(P=0.41$, Fig. $8 B)$. Therefore, after NB stimulation paired with a $19-\mathrm{kHz}$ tone, the percentage of PAF cortex that responded to high-frequency tones increased only modestly, whereas the percentage of PAF cortex that responded to low-frequency tones decreased significantly (Fig. 9).

\section{NB stimulation increased Al response to high- frequency tones}

Primary auditory cortex (A1) showed an expanded representation of high-frequency sounds after NB stimulation paired with the 19-kHz tone, confirming previous studies of NB-tone pairing (Kilgard and Merzenich 1998a). The percentage of A1
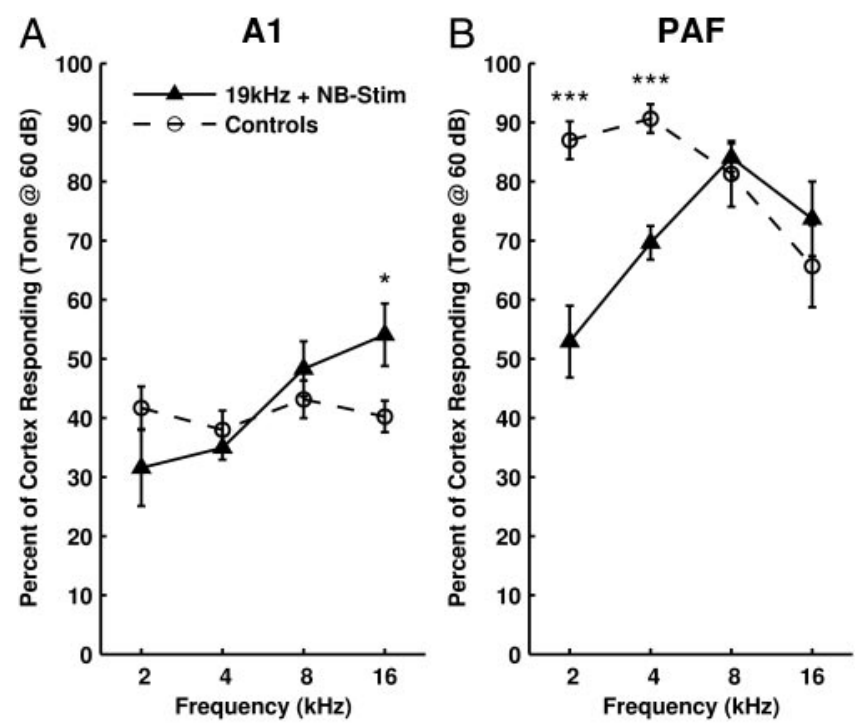

FIG. 8. Percentage of A1 and PAF that responds to several tones presented at $60 \mathrm{~dB}$ SPL. Average percentage of each field that responded to each tone frequency presented at $60 \mathrm{~dB}$ SPL is depicted. Whereas A1 $(A)$ showed an increase in the number of neurons that responded to high-frequency tones (such as $16 \mathrm{kHz}$ ), PAF $(B)$ sites showed a decrease in the number of neurons that responded to low-frequency tones $(2$ and $4 \mathrm{kHz})$. Asterisks indicate level of significance in a comparison between controls and experimentals: $* P<$ $0.05 ; * * P<0.01 ; * * * P<0.001$. sites that responded to a $16-\mathrm{kHz} 60 \mathrm{~dB}$ SPL tone increased, from $40 \pm 3.62 \%$ in control animals to $54.08 \pm 5.29 \%$ in experimental animals $(P=0.02)($ Fig. $8 A)$. There were similar increases in the percentage of $\mathrm{A} 1$ sites that responded to tones between 10 and $17 \mathrm{kHz}$ (at intensities between 50 and $70 \mathrm{~dB}$ SPL). In addition, the percentage of A1 sites that responded to low-frequency tones decreased slightly (percentage of A1 cortex responding to $2 \mathrm{kHz}$ : controls: $41.7 \pm 3.62 \%$; experimentals: $31.54 \pm 6.45 \%, P=0.13$, Fig. $8 A$ ). Unlike the plasticity observed in PAF, A1 reorganization was not accompanied by significant alterations in receptive field size (BW30: controls: $1.82 \pm 0.05$; experimentals: $1.78 \pm 0.05, P=0.61)$. Therefore NB-tone pairing in A1 appears to have created a shift of tuning curves toward the paired tone frequency, without changing receptive field sizes.

\section{Frequency-specific changes in PAF firing rate}

It is possible that NB-tone pairing increased the number of action potentials elicited by the paired $(19-\mathrm{kHz})$ tone without significantly increasing the area of PAF cortex that responded to that tone. The percentage of cortex measure used in this and previous publications (Kilgard and Merzenich 1998a; Kilgard et al. 2001; Pandya et al. 2005) would not detect such an increase because the measure takes into account only receptive field boundaries (i.e., tones are "in" or "out") and not variations in the evoked response to different tones within each site's receptive field. To determine whether NB-tone pairing increased responses to high-frequency tones, we quantified the mean response of all PAF sites in experimental and control animals to every presented frequency-intensity tone combination. At each site, the number of spikes evoked by each tone was averaged with the neighboring frequency and intensity steps $(5 \mathrm{~dB}$ above and below and 1/16th octave above and below each tone).

Pairing NB stimulation with a $19-\mathrm{kHz}$ tone did not increase the number of spikes elicited by high-frequency tones, but did result in a large decrease in the number of spikes elicited by low-frequency tones. In control animals, a $16-\mathrm{kHz} 60 \mathrm{~dB}$ SPL tone elicited $0.69 \pm 0.07$ spikes per PAF site, whereas in the experimental group the same tone elicited $0.64 \pm 0.06$ spikes $(P=0.64)$. In contrast, a $2-\mathrm{kHz} 60 \mathrm{~dB}$ SPL tone evoked $0.97 \pm 0.09$ spikes per site in controls compared with only $0.54 \pm 0.06$ spikes in experimental animals $(P=0.0002$, Fig. $10 A)$. Changes of similar magnitude and statistical significance were observed in the responses to most tones played at $<5 \mathrm{kHz}$ (Fig. 11). These results support our initial observation that NB-tone pairing caused a reduction in the bandwidth of PAF sites, but did not necessarily shift receptive fields toward the paired tone. If the reduction of bandwidth in PAF sites was the result of shifts of individual neurons within the multiunit clusters toward the paired frequency, we would have expected to see increased evoked responses to the paired tone. We saw no indication of increased responses to any high-frequency tone (Fig. 11). Previous studies of A1 that systematically evaluated this issue observed that changes in selectivity of multiunit responses closely mirrored the changes of well-sorted single units (Kilgard and Merzenich 1998a).

When sites were subdivided by whether they did or did not respond to the paired stimulus (Tone In and Tone Out, respec- 

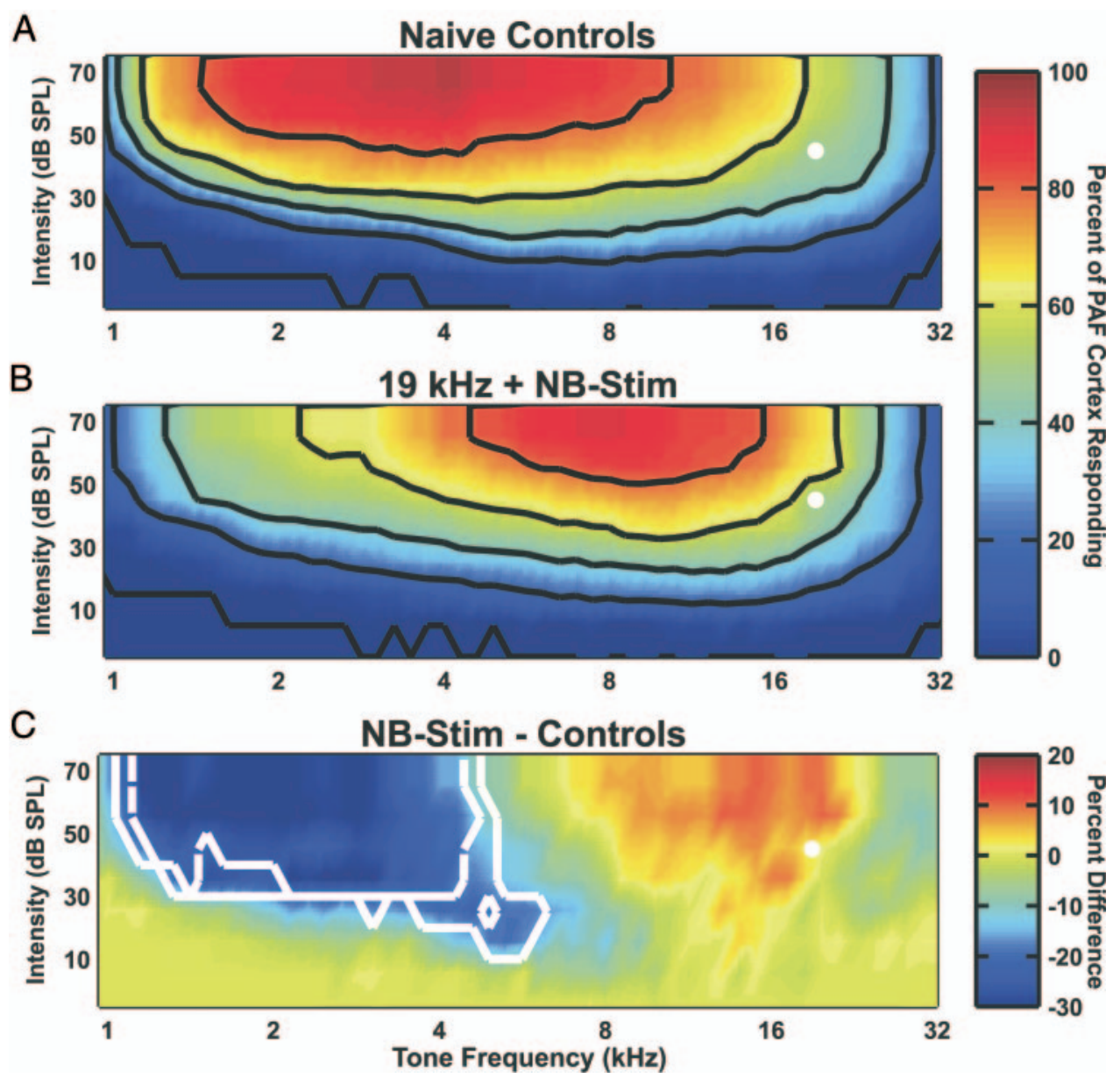

FIG. 9. Percentage of PAF that responded to all low-frequency tones decreased after NB-tone pairing. A: average percentage of PAF cortex in controls that responds to each tone frequency-intensity combination is shown. Contour lines on the plot indicate the tones that elicit responses from $0,20,40,60$, and $80 \%$ of PAF neurons. $B$ : average percentage of PAF cortex in experimental animals responding to each tone frequency-intensity combination. Contour lines (60 and $80 \%$ ) were shifted toward high frequencies in the experimental animals compared with controls. $C$ : difference in the percentage of PAF responding to each tone-intensity combination (experimental-controls) is shown. White lines delineate the frequency-intensity combinations with a significant decrease in the percentage of cortex responding after NB-stimulation pairing (solid: $P<0.05$; dashed: $P<0.01$ ). No increases in the percentage of cortex responding were statistically significant. White points in $A-C$ indicate the tone that was paired with NB stimulation in experimental animals (19 kHz at $50 \mathrm{~dB}$ SPL).
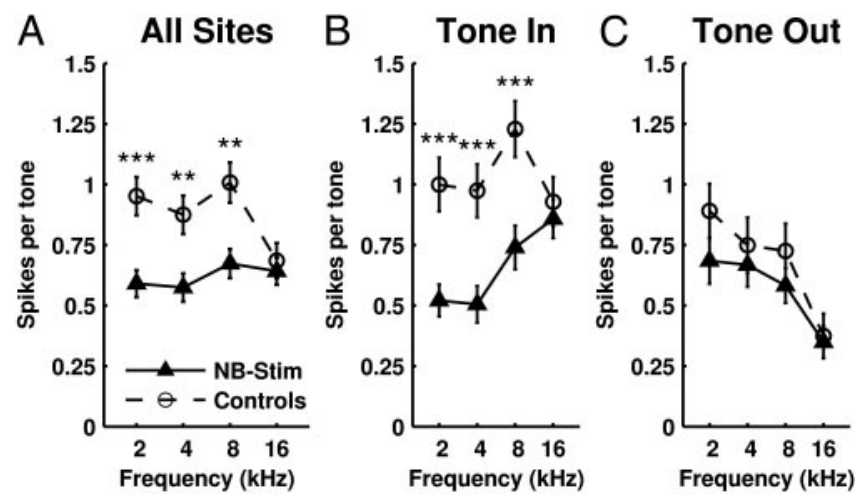

FIG. 10. Depiction of the number of spikes elicited by tones played at 60 dB SPL. $A$ : average evoked response for all PAF sites. $B$ and $C$ : responses of those subsets of sites that contained the paired tone within their receptive field $(B)$ or did not $(C)$. A decrease in the number of spikes elicited by lowfrequency tones $(A)$ was primarily caused by a decrease in responsiveness of the Tone In subset of sites $(B)$. Asterisks indicate level of significance: $* P<$ $0.05 ; * * P<0.01 ; * * * P<0.001$. tively), the decrease in response to low-frequency tones was found to originate primarily from the Tone In subset of sites (Fig. 10, $B$ and $C$ ). In control animals, Tone In sites responded to a 2-kHz 60 $\mathrm{dB}$ SPL tone with $0.99 \pm 0.11$ spike per PAF site, but after $\mathrm{NB}$-tone pairing, the same tone elicited only $0.52 \pm 0.06$ spike $(P=0.0002)$. Although there was some evidence for decreased response strength to low-frequency tones in the Tone Out subpopulation (spikes per PAF site: controls: $0.89 \pm 0.11$; experimentals: $0.68 \pm 0.09, P=0.16$, Fig. $10 C$ ), this decrease was small and not statistically reliable. The response to high-frequency tones was not increased in either the Tone In or Tone Out subgroups (Fig. 10, $B$ and $C$ ). This analysis, which required no judgments about tuning curve edges, supports our proposition that the primary effect of NB-stimulation pairing in PAF was to cause sites that responded to the $19-\mathrm{kHz}$ tone to become more selective by decreasing their responses to low- and mid-frequency tones (Fig. 11).

Spontaneous firing increased in both PAF and A1 after NBtone pairing. In PAF, the control group had a spontaneous firing rate of $2.75 \pm 0.16 \mathrm{~Hz}$, whereas the experimental group had a spontaneous rate of $4.68 \pm 0.25 \mathrm{~Hz}\left(P<10^{-4}\right)$. In A1, the control 


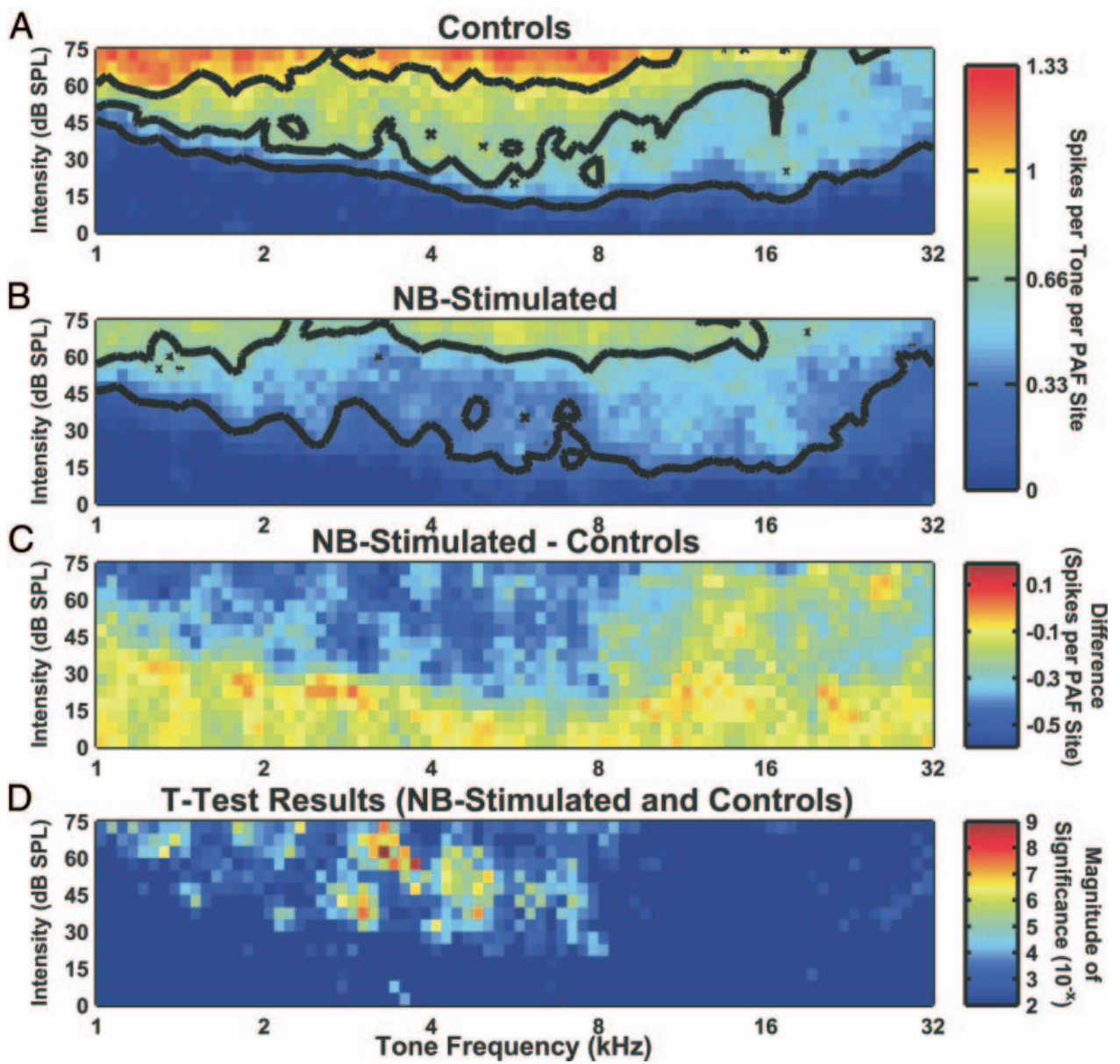

FIG. 11. Average number of spikes responding to each frequency-intensity combination per PAF site. For each site, the spontaneous rate (calculated as the activity to $0 \mathrm{~dB}$ SPL tones) was subtracted from the response to all the other frequency-tone combinations. $A$ : average number of spikes evoked from all control sites. $B$ : average number of spikes from all experimental sites. Black lines in $A$ and $B$ delineate the $0.5,0.75$, and 1 spike per tone boundaries on each plot. $C$ : subtraction of the average of the control sites $(A)$ from the average of the experimental sites $(B)$. A zero (orange) indicates that there was no difference between the 2 groups in the number of spikes evoked by the frequency-intensity combination. $D$ : result of $t$-test between the number of spikes evoked by each frequency-intensity combination in control and experimental sites. Color bar indicates degrees of significance: a value of 3 denotes $P<0.001$; a value of 4 denotes $P<0.0001$.

group's spontaneous firing rate was $3.74 \pm 00.16 \mathrm{~Hz}$, whereas the experimental group had a spontaneous rate of $4.62 \pm 0.21 \mathrm{~Hz}$ $(P=0.0009)$. The increase in spontaneous firing showed no evidence of frequency specificity in either PAF or A1.

D I S C US S I O N

\section{Summary of results}

NB stimulation paired with a $19-\mathrm{kHz}$ tone increased the cortical response to high-frequency tones relative to other tone frequencies in both primary and nonprimary auditory cortices. Consistent with earlier observations, the A1 representation of high frequencies increased without a significant decrease in the representation of low- or mid-frequency tones or change in average receptive field sizes (Kilgard and Merzenich 1998a; Kilgard et al. 2001). PAF showed a pattern of plasticity in response to NB-tone pairing that was distinctly different from that of A1. Rather than shifting tuning curves toward the paired tone, PAF sites became more selective. The principal effect in PAF after NBstimulation pairing was not an increase in the representation of the paired tone, but a decrease in the representation of low- or mid-frequency tones. Although we did not record from the same neurons before and after NB stimulation, it appears that sites that were responsive to the paired tone before NB stimulation increased their selectivity, whereas low-frequency sites remained unaltered.

\section{Changes in spontaneous firing and cortical plasticity}

We observed increased spontaneous activity in both PAF and A1 after NB-stimulation pairing. Increased spontaneous activity has been observed in several studies of NB-stimulation pairing using diverse types of paired auditory stimuli (Metherate and Ashe 1993; Pandya et al. 2005), although not all studies of NB-stimulation pairing have observed increased spontaneous firing rate (Kilgard et al. 2001). Direct application of acetylcholine onto cortical neurons increases spontaneous firing in some cells (Metherate and Weinberger 1990), implying that increased spontaneous activity may be a generalized effect of NB stimulation. In contrast, changes in receptive field properties such as frequency selectivity and response latency 
seem to be dependent on specific attributes of the auditory stimuli that were paired with NB stimulation (Kilgard et al. 2001).

\section{Previous studies of plasticity in nonprimary cortex}

Receptive field narrowing may be a common feature of plasticity in broadly tuned nonprimary cortical areas. Neurons in secondary cortical fields were more prone to bandwidth decreases than primary cortical neurons after tone-shock conditioning (Diamond and Weinberger 1986). In the ventroposterior area, which is similar to PAF in terms of response characteristics and location relative to A1, receptive fields were narrowed after stimulation of the ventral tegmental area (VTA) (Bao et al. 2001). These results are analogous to our observation that receptive field sizes in PAF were decreased after NB-tone pairing. However, secondary cortical areas do not always show receptive field narrowing when undergoing plasticity. Extensive training on an auditory frequency-discrimination task led to frequency-specific reorganization of secondary field SRAF (suprarhinal auditory field) in trained rats, but did not affect receptive field sizes (Polley et al. 2006). This difference may have been because receptive fields in SRAF are relatively narrow even in naïve animals or because of the sensory statistics associated with the behavioral tasks.

Receptive field size decreases have also been observed in secondary fields of the visual system after behavioral training. Training on an orientation-discrimination task leads to smaller receptive fields in V4 (Yang and Maunsell 2004), and discriminating complex stimuli led to smaller receptive fields in the inferotemporal cortex of monkeys (DiCarlo and Maunsell 2003). In both of these cases, plasticity was limited to neurons that were active during performance of the discrimination task, similar to our finding that PAF plasticity after NB-tone pairing may have been limited to sites that were activated by the paired stimulus.

\section{Models of plasticity}

The PAF plasticity observed in this study could result from changes occurring in at least three different locations: A1, auditory thalamus, or PAF. Plasticity in PAF could directly reflect map reorganization in A1. A1 neurons send direct, physiologically active projection to PAF (Hishida et al. 2007; Mascagni et al. 1993; Romanski and LeDoux 1993). These connections are necessary to produce driven activity in cat PAF (Kitzes and Hollrigel 1996). Therefore PAF receptive fields could be constructed from inputs from A1 neurons that are tuned to several different frequencies, from many locations across A1. After NB-tone pairing, receptive fields in A1 are shifted toward the paired frequency, and large areas of A1 cortex become tuned to the same range of frequencies. This would in turn cause PAF neurons to develop smaller receptive fields that are biased toward the paired frequency because large numbers of A1 neurons are now tuned to the paired tone. This model could explain the pattern of plasticity that we observed in PAF and could be used to make predictions about the results of future plasticity studies in PAF using more complex sounds based on known A1 results (Kilgard and Merzenich 1998b, 2002; Kilgard et al. 2001; Moucha et al. 2005; Pandya et al. 2005).
It is also possible that reorganization of the nonleminscal thalamus could explain the observed plasticity in PAF. Secondary cortical areas such as PAF receive direct inputs from the nonlemniscal (medial and dorsal) subdivisions of the thalamus (Arnault and Roger 1990; Kimura et al. 2003; Malmierca 2003; Winer et al. 1999). The medial and dorsal divisions of the thalamus have receptive field properties that are similar to PAF, such as large receptive fields and long response latencies (Aitkin and Webster 1971; Bordi and LeDoux 1994; Calford 1983). Both the medial and dorsal divisions of the thalamus exhibit shifts in receptive field tuning and sometimes reductions in receptive field sizes after classical conditioning (Edeline and Weinberger 1991, 1992). Even though NB does not have direct anatomical connections to the auditory thalamus (Hallanger et al. 1987), NB-tone pairing could alter receptive field properties in the medial geniculate body (MGB) through cortico-fugal connections from A1 to the auditory thalamus (Hazama et al. 2004; Kimura et al. 2005; Winer and Larue 1987).

Finally, PAF plasticity could be explained by reorganization of the intrinsic circuitry of PAF after NB-tone pairing. PAF receives inputs directly from NB and could undergo plasticity at the circuit level (Arnault and Roger 1990). Based on studies of A1 plasticity after NB-tone pairing, reorganization of PAF receptive fields could result from sharpening of excitatory fields, increased levels of inhibition in the cortical circuit, or a combination of the two (Dykes 1997; Froemke et al. 2006; Metherate and Ashe 1993; Metherate and Weinberger 1990). The plasticity that we observed in PAF after NB-tone pairing is likely the result of some combination of changes in A1, MGB, and PAF.

\section{Predictions for future studies}

Our earlier studies have shown that the type of sounds paired with NB stimulation determines the form of plasticity generated in A1 (Kilgard and Merzenich 1998b, 2002; Kilgard et al. 2001; Moucha et al. 2005; Pandya et al. 2005). Pairing temporally modulated tones decreases frequency selectivity in A1, whereas pairing tones with many different frequencies sharpens frequency tuning. If the A1 feedforward model outlined earlier is correct, PAF receptive field narrowing would follow any A1 frequency map expansion, but would not necessarily follow plasticity that narrows frequency bandwidth in A1 without changing tonotopy. Sounds that broaden A1 tuning curves would have relatively little effect on PAF neurons that already receive convergent inputs.

\section{Technical considerations}

The methods of our current study did not allow us to record from the same neurons before and after NB-stimulation pairing. The finding that only the Tone In subsets of neurons were different between control and experimental animals implies that PAF plasticity was restricted to neurons that were responsive to the paired tone before NB stimulation. However, it is also possible that the observed plasticity was caused by more generalized effects in which some PAF neurons shifted away from the paired tone (and thus joined the Tone Out group), whereas other PAF neurons shifted 
toward the paired tone (joining the Tone In group). Although we favor the first explanation because it is less complicated (i.e., one type of plasticity limited to the activated population), the second explanation cannot be excluded without recording from the same neurons before and after NB-tone pairing.

It should be noted that the map expansion recorded in A1 was not centered directly on the paired tone frequency (19 $\mathrm{kHz}$ ), but was instead centered on approximately $1 \mathrm{kHz}$ and extended from approximately 1 to $17 \mathrm{kHz}$. It is possible that 20 days of NB-tone pairing was not sufficient to induce a complete shift in tuning to the $19-\mathrm{kHz}$ tone. However, we feel that because of the challenge of characterizing two cortical fields in each individual animal, the full highfrequency border of A1 may not have been fully delineated in each experimental map. Prior studies of NB-stimulationinduced plasticity that were focused on mapping A1 exclusively observed A1 map expansions that were centered on the paired tone after a 20-day period of NB-tone pairing.

We did not control for the effect of sound exposure apart from NB stimulation. Previous plasticity studies have documented that the primary auditory cortex of adult rats is not changed after sound exposure to tones (Bao et al. 2004; Polley et al. 2004; Recanzone et al. 1993; Rutkowski and Weinberger 2005). However, there is still a possibility that the observed plasticity in PAF might have occurred apart from stimulation of NB.

All of the physiological recordings for this study were made under pentobarbital anesthesia. Several studies have indicated that anesthesia can change the response properties of auditory neurons (Gaese and Ostwald 2001; Rennaker et al. 2007; Zurita et al. 1994). In addition, some forms of plasticity are expressed only during the awake state, such as shifts in response properties during a difficult behavioral task (Fritz et al. 2005; Ito and Gilbert 1999; Li et al. 2004). Our observation that the changes in both A1 and PAF cortex caused by NB-tone pairing were present under deep anesthesia implies that the observed changes reflect plasticity in the circuitry of the auditory system and that feedback activity from higher associational areas may not be necessary for some forms of experience-dependent plasticity to be expressed.

In conclusion, this study demonstrates that stimulusspecific plasticity occurs in a nonprimary cortical area after NB-tone pairing. PAF sites showed a tendency to become selective for the paired stimulus at the exclusion of other frequencies. It has been speculated that secondary fields may be specialized for extracting behaviorally relevant features from complex stimuli (Rauschecker 1998) and that learning-induced plasticity in these areas enhances this specialization (Ghose 2004). The finding that receptive field narrowing has been observed in secondary cortical areas after both behavioral training and NB-tone pairing shows that this form of plasticity occurs after sensory experience paired with neuromodulatory inputs. Explicit task knowledge may not be necessary to achieve the increased specialization for trained stimuli observed in secondary cortex after behavioral training (DiCarlo and Maunsell 2003; Ghose 2004; Yang and Maunsell 2004). The plasticity we observed in PAF differs significantly from the concurrent plasticity we observed in A1, indicating that even simple stimuli can create complex patterns of plasticity across many stations of the auditory system. Recent behavioral and physiological studies have investigated how the primary auditory cortex processes complex, naturalistic stimuli, including speech sounds (Ohl and Scheich 1997; Reed et al. 2003; Sakai and Kudoh 2005; Steinschneider et al. 2003; Toro et al. 2005; Wang and Kadia 2001; Wetzel et al. 1998). To fully understand experience-dependent plasticity in the auditory system, it will be critical to systematically explore plasticity in both primary and nonprimary sensory cortices after exposure to complex stimuli. NB-stimulation pairing provides a strong experimental framework from which to understand how stimulus-specific plasticity influences all stages of sensory processing.

\section{A C K N OWLED GMEN TS}

Many thanks to D. Rathbun, J. Vasquez, and N. Engineer for assistance in collecting physiological data. Thank you to $\mathrm{H}$. Ho for help with NB-stimulation sessions.

Present address of P. Pandya: University of Illinois at Urbana-Champaign, 1401 West Green Street, Urbana, IL 61801.

\section{G R A N T S}

This research was supported by the James S. McDonnell Foundation.

\section{REFERENCES}

Aitkin LM, Webster WR. Tonotopic organization in the medial geniculate body of the cat. Brain Res 26: 402-405, 1971.

Arnault P, Roger M. Ventral temporal cortex in the rat: connections of secondary auditory areas Te2 and Te3. J Comp Neurol 302: 110-123, 1990.

Bakin JS, Weinberger NM. Induction of a physiological memory in the cerebral cortex by stimulation of the nucleus basalis. Proc Natl Acad Sci USA 93: 11219-11224, 1996.

Bao S, Chan VT, Merzenich MM. Cortical remodelling induced by activity of ventral tegmental dopamine neurons. Nature 412: 79-83, 2001.

Bao S, Chang EF, Woods J, Merzenich MM. Temporal plasticity in the primary auditory cortex induced by operant perceptual learning. Nat Neurosci 7: 974-981, 2004.

Bordi F, LeDoux JE. Response properties of single units in areas of rat auditory thalamus that project to the amygdala. I. Acoustic discharge patterns and frequency receptive fields. Exp Brain Res 98: 261-274, 1994.

Brown M, Irvine DR, Park VN. Perceptual learning on an auditory frequency discrimination task by cats: association with changes in primary auditory cortex. Cereb Cortex 14: 952-965, 2004.

Buonomano DV, Merzenich MM. Cortical plasticity: from synapses to maps. Annu Rev Neurosci 21: 149-186, 1998.

Butt AE, Hodge GK. Simple and configural association learning in rats with bilateral quisqualic acid lesions of the nucleus basalis magnocellularis. Behav Brain Res 89: 71-85, 1997.

Calford MB. The parcellation of the medial geniculate body of the cat defined by the auditory response properties of single units. J Neurosci 3: 23502364, 1983

Conner JM, Culberson A, Packowski C, Chiba AA, Tuszynski MH. Lesions of the basal forebrain cholinergic system impair task acquisition and abolish cortical plasticity associated with motor skill learning. Neuron 38: 819-829, 2003.

Diamond DM, Weinberger NM. Physiological plasticity of single neurons in auditory cortex of the cat during acquisition of the pupillary conditioned response: II. Secondary field (AII). Behav Neurosci 98: 189-210, 1984.

Diamond DM, Weinberger NM. Classical conditioning rapidly induces specific changes in frequency receptive fields of single neurons in secondary and ventral ectosylvian auditory cortical fields. Brain Res 372: 357-360, 1986.

DiCarlo JJ, Maunsell JH. Anterior inferotemporal neurons of monkeys engaged in object recognition can be highly sensitive to object retinal position. J Neurophysiol 89: 3264-3278, 2003. 
Dimyan MA, Weinberger NM. Basal forebrain stimulation induces discriminative receptive field plasticity in the auditory cortex. Behav Neurosci 113: 691-702, 1999.

Doron NN, Ledoux JE, Semple MN. Redefining the tonotopic core of rat auditory cortex: physiological evidence for a posterior field. J Comp Neurol 453: 345-360, 2002.

Dykes RW. Mechanisms controlling neuronal plasticity in somatosensory cortex. Can J Physiol Pharmacol 75: 535-545, 1997.

Edeline JM, Weinberger NM. Subcortical adaptive filtering in the auditory system: associative receptive field plasticity in the dorsal medial geniculate body. Behav Neurosci 105: 154-175, 1991.

Edeline JM, Weinberger NM. Associative retuning in the thalamic source of input to the amygdala and auditory cortex: receptive field plasticity in the medial division of the medial geniculate body. Behav Neurosci 106: 81-105, 1992.

Fritz JB, Elhilali M, Shamma SA. Differential dynamic plasticity of A1 receptive fields during multiple spectral tasks. J Neurosci 25: 7623-7635, 2005.

Froemke RC, Merzenich MM, Schreiner CE. Synaptic basis of cortical receptive field plasticity. Poster 536.4/I14, 36th Annu Meeting Soc Neurosci, Atlanta, GA, Oct. 14-18, 2006.

Gaese BH, Ostwald J. Anesthesia changes frequency tuning of neurons in the rat primary auditory cortex. J Neurophysiol 86: 1062-1066, 2001.

Ghose GM. Learning in mammalian sensory cortex. Curr Opin Neurobiol 14: 513-518, 2004

Gilbert CD. Learning and receptive field plasticity. Proc Natl Acad Sci USA 93: 10546-10547, 1996.

Hallanger AE, Levey AI, Lee HJ, Rye DB, Wainer BH. The origins of cholinergic and other subcortical afferents to the thalamus in the rat. J Comp Neurol 262: 105-124, 1987.

Hazama M, Kimura A, Donishi T, Sakoda T, Tamai Y. Topography of corticothalamic projections from the auditory cortex of the rat. Neuroscience 124: 655-667, 2004.

Hishida R, Kamatani D, Kitaura H, Kudoh M, Shibuki K. Functional local connections with differential activity-dependence and critical periods surrounding the primary auditory cortex in rat cerebral slices. Neuroimage 34: 679-693, 2007.

Ito M, Gilbert CD. Attention modulates contextual influences in the primary visual cortex of alert monkeys. Neuron 22: 593-604, 1999.

Ji W, Gao E, Suga N. Effects of acetylcholine and atropine on plasticity of central auditory neurons caused by conditioning in bats. J Neurophysiol 86: 211-225, 2001.

Kelly JB, Masterton B. Auditory sensitivity of the albino rat. J Comp Physiol Psychol 91: 930-936, 1977.

Kilgard MP, Merzenich MM. Cortical map reorganization enabled by nucleus basalis activity. Science 279: 1714-1718, 1998a.

Kilgard MP, Merzenich MM. Plasticity of temporal information processing in the primary auditory cortex. Nat Neurosci 1: 727-731, 1998b.

Kilgard MP, Merzenich MM. Distributed representation of spectral and temporal information in rat primary auditory cortex. Hear Res 134: 16-28, 1999.

Kilgard MP, Merzenich MM. Order-sensitive plasticity in adult primary auditory cortex. Proc Natl Acad Sci USA 99: 3205-3209, 2002.

Kilgard MP, Pandya PK, Vazquez J, Gehi A, Schreiner CE, Merzenich MM. Sensory input directs spatial and temporal plasticity in primary auditory cortex. J Neurophysiol 86: 326-338, 2001.

Kimura A, Donishi T, Okamoto K, Tamai Y. Topography of projections from the primary and non-primary auditory cortical areas to the medial geniculate body and thalamic reticular nucleus in the rat. Neuroscience 135: $1325-1342,2005$.

Kimura A, Donishi T, Sakoda T, Hazama M, Tamai Y. Auditory thalamic nuclei projections to the temporal cortex in the rat. Neuroscience 117: 1003-1016, 2003

Kitzes LM, Hollrigel GS. Response properties of units in the posterior auditory field deprived of input from the ipsilateral primary auditory cortex. Hear Res 100: 120-130, 1996.

Li W, Piech V, Gilbert CD. Perceptual learning and top-down influences in primary visual cortex. Nat Neurosci 7: 651-657, 2004.

Malmierca MS. The structure and physiology of the rat auditory system: an overview. Int Rev Neurobiol 56: 147-211, 2003.

Mascagni F, McDonald AJ, Coleman JR. Corticoamygdaloid and corticocortical projections of the rat temporal cortex: a Phaseolus vulgaris leucoagglutinin study. Neuroscience 57: 697-715, 1993.
Metherate R, Ashe JH. Nucleus basalis stimulation facilitates thalamocortical synaptic transmission in the rat auditory cortex. Synapse 14: 132-143, 1993.

Metherate R, Weinberger NM. Cholinergic modulation of responses to single tones produces tone-specific receptive field alterations in cat auditory cortex. Synapse 6: 133-145, 1990.

Moucha R, Pandya PK, Engineer ND, Rathbun DL, Kilgard MP. Background sounds contribute to spectrotemporal plasticity in primary auditory cortex. Exp Brain Res 162: 417-427, 2005.

Ohl FW, Scheich H. Orderly cortical representation of vowels based on formant interaction. Proc Natl Acad Sci USA 94: 9440-9444, 1997.

Pandya PK, Moucha R, Engineer ND, Rathbun DL, Vazquez J, Kilgard MP. Asynchronous inputs alter excitability, spike timing, and topography in primary auditory cortex. Hear Res 203: 10-20, 2005.

Polley DB, Heiser MA, Blake DT, Schreiner CE, Merzenich MM. Associative learning shapes the neural code for stimulus magnitude in primary auditory cortex. Proc Natl Acad Sci USA 101: 16351-16356, 2004.

Polley DB, Steinberg EE, Merzenich MM. Perceptual learning directs auditory cortical map reorganization through top-down influences. $J \mathrm{Neu}$ rosci 26: 4970-4982, 2006.

Rauschecker JP. Parallel processing in the auditory cortex of primates. Audiol Neurootol 3: 86-103, 1998.

Recanzone GH, Merzenich MM, Jenkins WM. Frequency discrimination training engaging a restricted skin surface results in an emergence of a cutaneous response zone in cortical area 3a. J Neurophysiol 67: 1057-1070, 1992a.

Recanzone GH, Merzenich MM, Jenkins WM, Grajski KA, Dinse HR. Topographic reorganization of the hand representation in cortical area $3 \mathrm{~b}$ owl monkeys trained in a frequency-discrimination task. J Neurophysiol 67: 1031-1056, 1992b.

Recanzone GH, Schreiner CE, Merzenich MM. Plasticity in the frequency representation of primary auditory cortex following discrimination training in adult owl monkeys. J Neurosci 13: 87-103, 1993.

Reed P, Howell P, Sackin S, Pizzimenti L, Rosen S. Speech perception in rats: use of duration and rise time cues in labeling of affricate/fricative sounds. J Exp Anal Behav 80: 205-215, 2003.

Rennaker RL, Carey HL, Anderson SE, Sloan AM, Kilgard MP. Anesthesia suppresses nonsynchronous responses to repetitive broadband stimuli. Neuroscience 145: 357-369, 2007.

Richardson RT, DeLong MR. Electrophysiological studies of the functions of the nucleus basalis in primates. Adv Exp Med Biol 295: 233-252, 1991.

Romanski LM, LeDoux JE. Information cascade from primary auditory cortex to the amygdala: corticocortical and corticoamygdaloid projections of temporal cortex in the rat. Cereb Cortex 3: 515-532, 1993.

Rutkowski RG, Miasnikov AA, Weinberger NM. Characterisation of multiple physiological fields within the anatomical core of rat auditory cortex. Hear Res 181: 116-130, 2003.

Rutkowski RG, Weinberger NM. Encoding of learned importance of sound by magnitude of representational area in primary auditory cortex. Proc Natl Acad Sci USA 102: 13664-13669, 2005.

Sakai M, Kudoh M. Characteristics of sound discrimination enhancement after sound exposure in adult rats. Behav Neurosci 119: 961-973, 2005.

Steinschneider M, Fishman YI, Arezzo JC. Representation of the voice onset time (VOT) speech parameter in population responses within primary auditory cortex of the awake monkey. J Acoust Soc Am 114: 307-321, 2003.

Toro JM, Trobalon JB, Sebastian-Galles N. Effects of backward speech and speaker variability in language discrimination by rats. $J$ Exp Psychol Anim Behav Process 31: 95-100, 2005.

Wang X, Kadia SC. Differential representation of species-specific primate vocalizations in the auditory cortices of marmoset and cat. J Neurophysiol 86: 2616-2620, 2001.

Weinberger NM. Physiological memory in primary auditory cortex: characteristics and mechanisms. Neurobiol Learn Mem 70: 226-251, 1998.

Weinberger NM. Associative representational plasticity in the auditory cortex: a synthesis of two disciplines. Learn Mem 14: 1-16, 2007.

Weinberger NM, Bakin JS. Learning-induced physiological memory in adult primary auditory cortex: receptive fields plasticity, model, and mechanisms. Audiol Neurootol 3: 145-167, 1998.

Weinberger NM, Hopkins W, Diamond DM. Physiological plasticity of single neurons in auditory cortex of the cat during acquisition of the 
pupillary conditioned response: I. Primary field (AI). Behav Neurosci 98: 171-188, 1984.

Wetzel W, Ohl FW, Wagner T, Scheich H. Right auditory cortex lesion in Mongolian gerbils impairs discrimination of rising and falling frequencymodulated tones. Neurosci Lett 252: 115-118, 1998.

Winer JA, Larue DT. Patterns of reciprocity in auditory thalamocortical and corticothalamic connections: study with horseradish peroxidase and autoradiographic methods in the rat medial geniculate body. J Comp Neurol 257: 282-315, 1987.
Winer JA, Sally SL, Larue DT, Kelly JB. Origins of medial geniculate body projections to physiologically defined zones of rat primary auditory cortex. Hear Res 130: 42-61, 1999.

Yang T, Maunsell JH. The effect of perceptual learning on neuronal responses in monkey visual area V4. J Neurosci 24: 1617-1626, 2004.

Zurita P, Villa AE, de Ribaupierre Y, de Ribaupierre F, Rouiller EM. Changes of single unit activity in the cat's auditory thalamus and cortex associated to different anesthetic conditions. Neurosci Res 19: 303-316, 1994. 